\title{
ALGORITMA K-MEDOIDS UNTUK PENENTUAN STRATEGI PEMASARAN PRODUK
}

\author{
Wiwit Agus Triyanto \\ Fakultas Teknik, Program Studi Sistem Informasi \\ Universitas Muria Kudus \\ Email: at.wiwit@yahoo.co.id
}

\begin{abstract}
ABSTRAK
Strategi pemasaran produk merupakan hal yang sangat penting bagi perusahaan dimana strategi pemasaran merupakan pendekatan pokok yang digunakan oleh unit bisnis dalam mencapai sasaran yang di dalamnya tercantum keputusan-keputusan mengenai target pasar, penempatan produk, bauran pemasaran, serta tingkat biaya pemasaran yang diperlukan. Untuk dapat melakukan strategi pemasaran produk yang lebih efektif dan effisien, maka perlu dilakukan pengolahan data penjualan. Metode pengolahan data seperti ini sering disebut sebagai data mining. Pada penelitian ini akan menggunakan algoritma $K$-Medoids untuk pengelompokan data penjualan, sehingga akan ditemukan informasi yang dapat digunakan untuk penentuan strategi pemasaran produk yang tepat. Hasil dari penelitian ini menghasilkan 5 cluster dengan cluster pertama terdiri dari 909 record transaksi, cluster kedua terdiri dari 166 record transaksi, cluster ketiga terdiri dari 66 record transaksi, cluster keempat terdiri dari 132 record transaksi, cluster kelima terdiri dari 87 record transaksi. Strategi pemasaran produk dapat dilakukan dengan melakukan promosi pada cluster kelima yang memiliki kombinasi jumlah barang dibeli yang paling tinggi
\end{abstract}

Kata kunci: strategi, pemasaran, produk, cluster, k-medoids

\begin{abstract}
Product marketing strategy is very important for companies where the marketing strategy is the basic approach used by the business unit in achieving the stated objectives in which decisions about the target market, product positioning, marketing mix, as well as the necessary level of marketing costs. To be able to do product marketing strategies more effective and efficient, it is necessary to processing of sales data. Data processing methods are often referred to as data mining. This research will use the KMedoids algorithm for clustering of sales data, so it will be found that the information can be used to determine the right product marketing strategy. Results from this study resulted in five clusters with the first cluster consists of 909 records of transactions, the second cluster consists of 166 records of transactions, the third cluster consists of 66 record the transaction, the fourth cluster consists of 132 records of transactions, the fifth cluster consisting of 87 record the transaction. Product marketing strategy can be done with promotions on the fifth cluster that has a combination of the number of items purchased highest.
\end{abstract}

Keywords: strategy, marketing, product, cluster, $k$-medoids.

\section{PENDAHULUAN}

Strategi pemasaran produk merupakan hal yang sangat penting bagi perusahaan dimana strategi pemasaran merupakan suatu cara mencapai tujuan dari sebuah perusahaan. Strategi pemasaran adalah pendekatan pokok yang digunakan oleh unit bisnis di dalam mencapai sasaran yang di dalamnya tercantum keputusan-keputusan mengenai target pasar, penempatan produk, bauran pemasaran, serta tingkat biaya pemasaran yang diperlukan.

Untuk dapat melakukan pemasaran produk yang lebih efektif dan effisien, maka perlu dilakukan pengolahan data penjualan. Data yang telah didapatkan akan diolah untuk mengetahui pola dari data, sehingga dapat di ambil informasi yang tersembunyi dari data tersebut. Metode pengolahan data seperti ini sering disebut sebagai data mining. Pada penelitian ini analisa data mining dilakukan dengan menggunakan metode clustering.

Metode untuk melakukan clustering dapat dikategorikan menjadi empat metode, yaitu: partitioning, hierarchical, grid-based and model-based. Clustering berbasis partitioning menghasilkan partisi dari data 
sehingga objek dalam cluster lebih mirip satu sama lain daripada objek yang ada dalam cluster lain. $K$ Means dan K-Medoids adalah contoh dari metode partitioning. Algoritma K-Means sensitif terhadap outlier karena objek dengan nilai yang sangat besar dapat secara substansial mendistorsi distribusi data. Untuk mengambil nilai rata-rata dari objek dalam sebuah cluster sebagai titik acuan, medoid dapat digunakan, yang merupakan objek dalam sebuah cluster yang paling terpusat. Strategi dasar dari algoritma clustering K-Medoids adalah untuk menemukan k cluster dalam n objek dengan pertama kali secara arbitrarily menemukan wakil dari objek (medoid) untuk tiap-tiap cluster [1].

Pada penelitian ini akan menggunakan algoritma $K$-Medoids untuk pengelompokan data penjualan, sehingga akan ditemukan informasi yang dapat digunakan untuk penentuan strategi pemasaran produk yang tepat.

\section{METODOLOGI}

Metode penelitian dalam penelitian ini menggunakan metode eksperimen dengan tahapan seperti berikut:

a. Pengumpulan data

b. Pengolahan data awal

c. Penerapan algoritma

d. Evaluasi hasil

e. Dokumentasi eksperimen

Adapun skema alur tahapan penelitian ini ditunjukan pada gambar 1 .

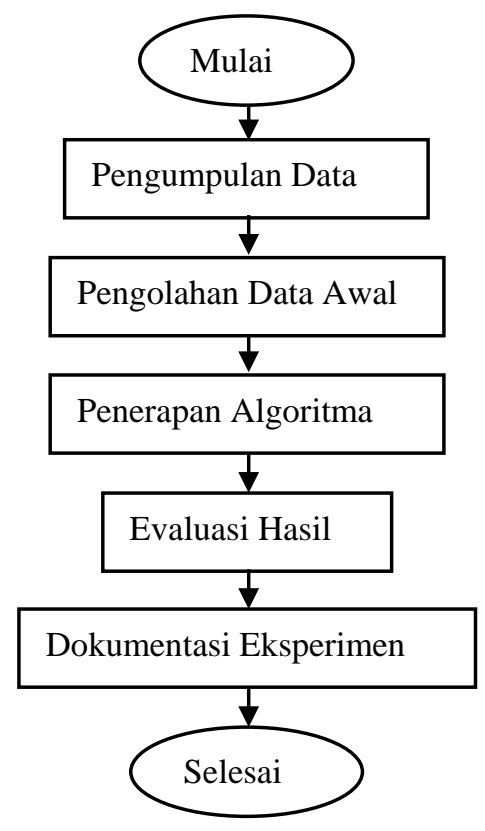

Gambar 1. Skema Alur Tahapan Penelitian

\section{HASIL DAN PEMBAHASAN}

\subsection{Pengumpulan Data}

Teknik pengumpulan data dilakukan dengan mengambil dataset transaksi penjualan pada sebuah supermarket. Terdapat 304 atribut yang 303 merupakan item/barang dan salah satunya merupakan ID transaksi penjualan. Terdiri dari 1361 record transaksi. Adapun contoh data dari dataset dapat dilihat pada tabel 1 .

\begin{tabular}{lcccccc} 
Tabel 1. Contoh Dataset \\
\hline Basket ID & Lemons & $\begin{array}{c}\text { Standard } \\
\text { coffee }\end{array}$ & $\begin{array}{c}\text { Frozen Chicken } \\
\text { Wings }\end{array}$ & $\begin{array}{c}\text { 98pct. Fat Free } \\
\text { Hamburger }\end{array}$ & $\begin{array}{c}\text { Sugar } \\
\text { Cookies }\end{array}$ & $\cdots$ \\
\hline $\mathbf{C 1 1 8 6 7}$ & false & false & true & true & false & $\cdots$ \\
$\mathbf{C 5 0 9 6}$ & false & false & false & true & false & $\cdots$ \\
$\mathbf{C 4 2 9 5}$ & false & false & false & false & false & $\cdots$ \\
$\mathbf{C 2 8 3 7}$ & true & false & false & false & true & $\cdots$ \\
$\mathbf{C 2 6 9 3}$ & true & false & true & false & false & $\ldots .$. \\
\hline
\end{tabular}


Keterangan

.... $\quad$....

... $\quad$...

...

....

... $\quad$...

a. Basket ID merupakan ID Transaksi penjualan barang.

b. Lemons, Standard coffee, Frozen Chicken Wings, 98pct. Fat Free Hamburger, Sugar Cookies merupakan barang-barang yang dijual di Supermarket.

c. False menandakan bahwa barang tersebut tidak dibeli oleh pembeli.

d. True menandakan bahwa barang tersebut dibeli oleh pembeli.

\subsection{Pengolahan Data Awal}

Data yang sudah dikumpulkan akan diolah dengan beberapa tahap sehingga menjadi sebuah dataset yang akan diimplementasikan terhadap metode-metode data mining. Semua record transaksi yang ada pada dataset penjualan digunakan dalam tahap pengolahan data.Tahapan pengolahan data yang dilakukan yaitu:

a. Data Preprocessing

Data Preprocessing yaitu dilakukan pembersihan dan persiapan data untuk menghilangkan kosistensi data, data tidak lengkap dan redundant data yang terdapat pada data awal. Data Preprocessing juga melakukan pengubahan status barang yang semula true / false menjadi 1 / 0 , yang akan digunakan untuk proses asosiasi.

b. Menghitung Jumlah Barang yang Dibeli / Tidak Dibeli

Penghitungan jumlah barang yang dibeli maupun yang tidak dibeli dilakukan dengan menambah 2 atribut di dalam dataset, kedua atribut tersebut digunakan untuk melakukan proses clustering data.

Adapun hasil perhitungan jumlah beli.tidak beli ditunjukan pada gambar 2 .

\begin{tabular}{|c|c|c|c|c|c|}
\hline Basket ID & Jumlah Barang yang dibeli & Jumlah Barang yang tak dibeli & Hair Conditioner & Lemons & Standard coffee \\
\hline C11867 & 1 & 302 & 0 & 0 & 0 \\
\hline C5096 & 2 & 301 & 0 & 0 & 0 \\
\hline C4295 & 1 & 302 & 0 & 0 & 0 \\
\hline C2837 & 1 & 302 & 0 & 0 & 0 \\
\hline C2693 & 1 & 302 & 0 & 0 & 0 \\
\hline С3497 & 1 & 302 & 0 & 0 & 0 \\
\hline C2696 & 1 & 302 & 0 & 0 & 0 \\
\hline C1895 & 17 & 286 & 0 & 0 & 0 \\
\hline C9524 & 1 & 302 & 0 & 0 & 0 \\
\hline
\end{tabular}

Gambar 2. Menghitung Jumlah Beli / Tidak beli

\subsection{Penerapan Algoritma}

Untuk melakukan clustering dengan metode partisi dapat menggunakan K-Means dan K-Medoids. $K$-Means merupakan suatu algoritma pengclusteran yang cukup sederhana yang mempartisi dataset kedalam beberapa cluster $\mathrm{k}$ [2].

Algortima K-Medoids, juga dikenal sebagai partitioning around Medoids, adalah varian dari metode K-Means. Hal ini didasarkan pada penggunaan Medoids bukan dari pengamatan mean yang dimiliki oleh setiap cluster, dengan tujuan mengurangi sensitivitas dari partisi yang dihasilkan sehubungan dengan nilai-nilai ekstrim yang ada dalam dataset [3].

Algoritma K-Medoids hadir untuk mengatasi kelemahan Algoritma K-Means yang sensitif terhadap outlier karena suatu objek dengan suatu nilai yang besar mungkin secara substansial menyimpang dari distribusi data [4]. Menurut Han dan Kamber, algoritma K-Medoids adalah sebagai berikut [4]:

a. Secara acak pilih $k$ objek pada sekumpulan $n$ objek sebagai medoid.

b. Ulangi:

c. Tempatkan objek non-medoid ke dalam cluster yang paling dekat dengan medoid.

d. Secara acak pilih Orandom: sebuah objek non-medoid.

e. Hitung total cost, $S$, dari pertukaran medoid oj dengan Orandom.

f. Jika $S<0$ maka tukar oj dengan Orandom untuk membentuk sekumpulan $k$ objek baru sebagai medoid.

g. Hingga tidak ada perubahan. 


\subsection{Evaluasi Hasil}

Dari hasil eksperimen clustering data penjualan, diperoleh grafik seperti yang ditunjukan pada gambar 3.

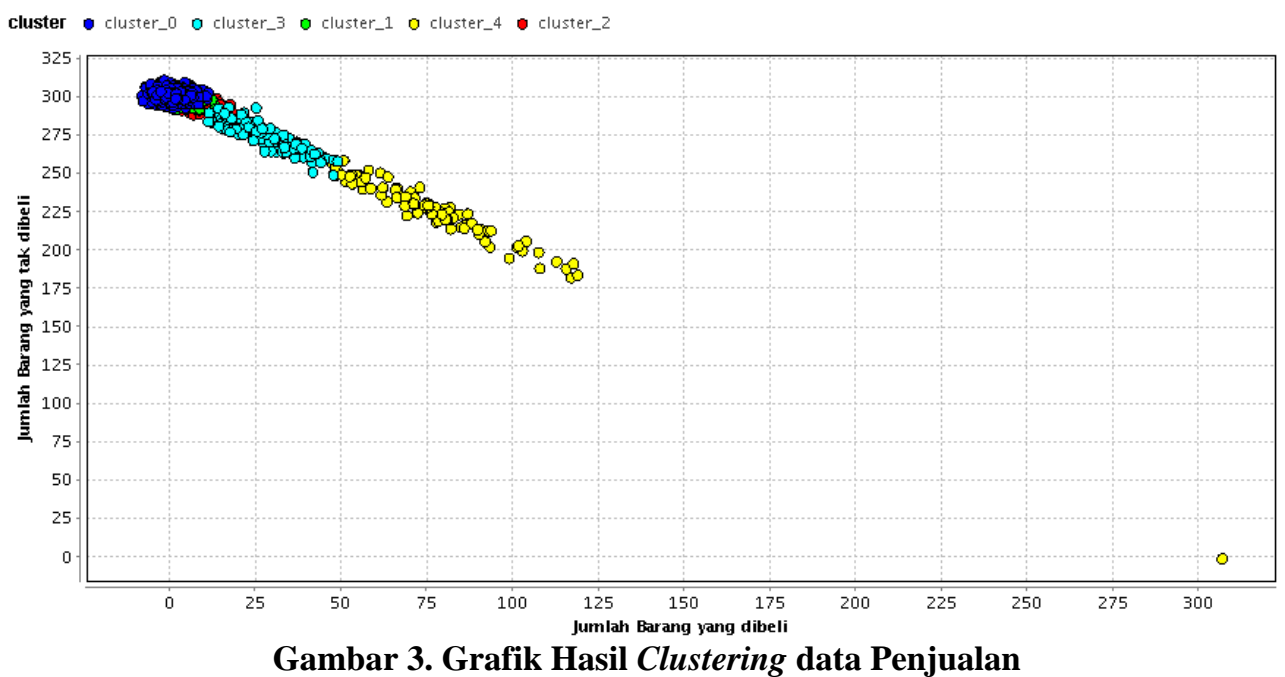

Informasi yang bisa diperoleh dari hasil proses clustering tersebut adalah pada transaksi penjualan yang semula terdiri dari 1360 record transaksi, dapat dikelompokkan menjadi 5 cluster:

a. Cluster pertama terdiri dari 909 record transaksi, berisi transaksi yang memiliki jumlah barang yang dibeli sekitar 1 - 2; dan jumlah barang yang tidak dibeli sekitar 301 - 302.

b. Cluster kedua terdiri dari 166 record transaksi, berisi transaksi yang memiliki jumlah barang yang dibeli sekitar 3 - 7; dan jumlah barang yang tidak dibeli sekitar 296 - 300.

c. Cluster ketiga terdiri dari 66 record transaksi, berisi transaksi yang memiliki jumlah barang yang dibeli sekitar 8 - 14; dan jumlah barang yang tidak dibeli sekitar $289-295$.

d. Cluster keempat terdiri dari 132 record transaksi, berisi transaksi yang memiliki jumlah barang yang dibeli sekitar $15-48$; dan jumlah barang yang tidak dibeli sekitar 255-288.

e. Cluster kelima terdiri dari 87 record transaksi, berisi transaksi yang memiliki jumlah barang yang dibeli sekitar 49 -303; dan jumlah barang yang tidak dibeli sekitar 0-254.

\subsection{Dokumentasi Eksperimen}

Dataset diambil dari data penjualan dalam bentuk excel diimport ke dalam rapid miner. Adapun hasil import data dari dataset ditunjukan pada gambar 4.

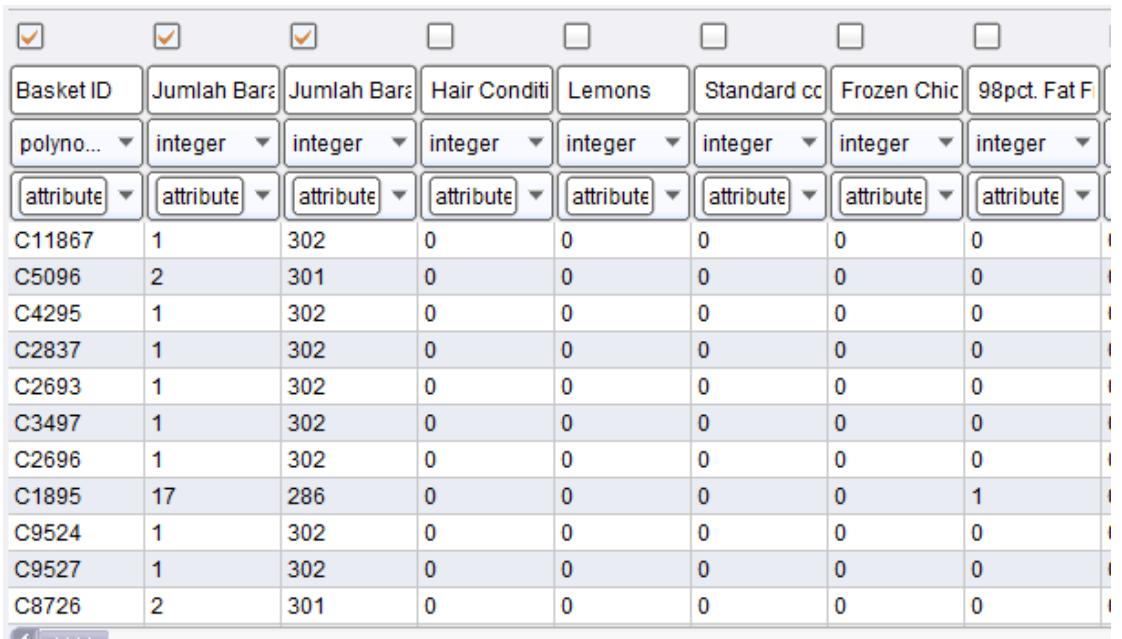

Gambar 4. Import Data Dari Dataset 
Kemudian data yang sudah diimport dilakukan proses clustering dengan membagi data tersebut menjadi 5 cluster $(\mathrm{k})$. Hasil dari proses clustering tersebut akan di eksport dalam bentuk file excel. Adapun proses clustering data ditunjukan pada gambar 5.

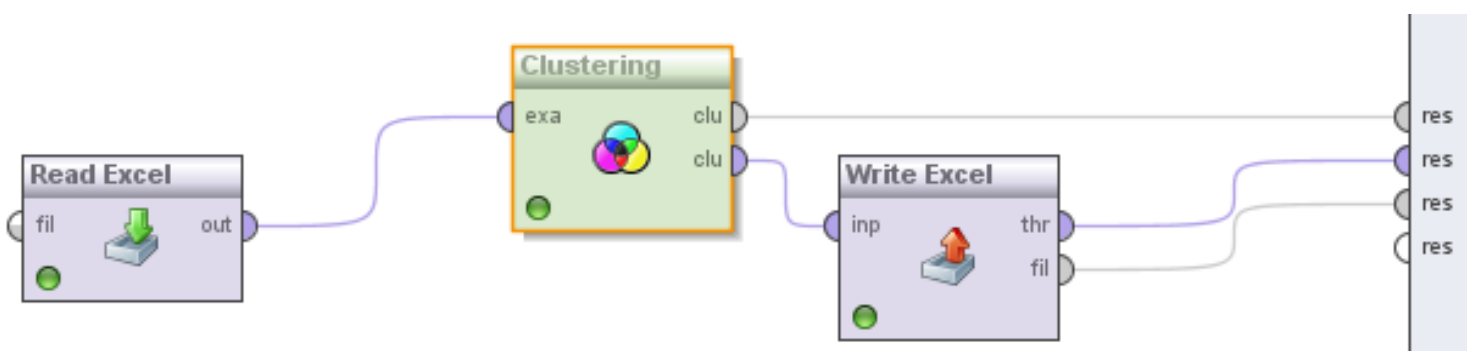

Gambar 5. Proses Clustering Data

Adapun hasil clustering data ditunjukan pada gambar 6.

\begin{tabular}{|l|l|l|l|l|}
\hline Row No. & \multicolumn{1}{|c|}{ Basket ID } & cluster & Jumlah Barang yang dibeli & Jumlah Barang yang tak dibeli \\
\hline 1 & C11867 & cluster_0 & 1 & 302 \\
\hline 2 & C5096 & cluster_0 & 2 & 301 \\
\hline 3 & C4295 & cluster_0 & 1 & 302 \\
\hline 4 & C2837 & cluster_0 & 1 & 302 \\
\hline 5 & C2693 & cluster_0 & 1 & 302 \\
\hline 6 & C3497 & cluster_0 & 1 & 302 \\
\hline 7 & C2696 & cluster_0 & 1 & 302 \\
\hline 8 & C1895 & cluster_3 & 17 & 286 \\
\hline 9 & C9524 & cluster_0 & 1 & 302 \\
\hline 10 & C9527 & cluster_0 & 1 & 302 \\
\hline 11 & C8726 & cluster_0 & 2 & 301 \\
\hline 12 & C9383 & cluster_0 & 2 & 301 \\
\hline 13 & C8582 & cluster_3 & 18 & 285 \\
\hline 14 & C10133 & cluster_3 & 16 & 287 \\
\hline 15 & C6983 & cluster_0 & 1 & 302 \\
\hline 16 & C3641 & cluster_1 & 3 & 300 \\
\hline 17 & C5246 & cluster_0 & 1 & 302 \\
\hline 18 & C10136 & cluster_0 & 1 & 302 \\
\hline 19 & C7787 & cluster_0 & 1 & 302 \\
\hline & & & & \\
\hline
\end{tabular}

\section{Gambar 6. Hasil Clustering Data}

\section{KESIMPULAN}

Dari hasil penelitian yang telah dilakukan dapat disimpulkan sebagai berikut:

a. Pengelompokan menghasilkan 5 cluster dengan Cluster pertama terdiri dari 909 record transaksi, Cluster kedua terdiri dari 166 record transaksi, Cluster ketiga terdiri dari 66 record transaksi, Cluster keempat terdiri dari 132 record transaksi, Cluster kelima terdiri dari 87 record transaksi.

b. Strategi pemasaran produk dapat dilakukan dengan melakukan promosi pada cluster kelima yang memiliki kombinasi jumlah barang dibeli yang paling tinggi. 


\section{DAFTAR PUSTAKA}

[1] T. Velmurugan, "Efficiency of k-Means and K-Medoids Algorithms for Clustering Arbitrary Data Points," International Journal Computer Technology \& Applications, vol. 3, 2012, pp. 1758-1764.

[2] X. Wu, V. Kumar, J.R. Quinlan, J. Ghosh, Q. Yang, H. Motoda, G.J. Mclachlan, A. Ng, B. Liu, P.S. Yu, Z.Z. Michael, S. David, and J.H. Dan, "Top 10 algorithms in data mining," Knowledge and Information Systems, 2008, pp. 1-37.

[3] C. Vercellis, Business Intelligence: Data mining and Optimization for Decision Making, Milan: WILEY, 2009.

[4] J. Han and M. Kamber, Data mining: Concepts and Techniques, Morgan Kaufmann, 2006. 